\title{
Hacia una mirada ecocrítica de la Literatura
} Hispanoamericana

Toward an ecocritical analysis of contemporary Spanish American literary texts

\section{Juan Gabriel Araya Grandón ${ }^{1}$}

Universidad del Bío-Bío, Chillán, Chile

jaraya@ubiobio.cl | juanarayagrandon@hotmail.com

[Seamos conscientes de que] la civilización

tiene sus raíces en la naturaleza,

que moldeó la cultura humana e influyó en todas las obras artísticas y

científicas,

y que la vida en armonía con la literatura ofrece al hombre

posibilidades óptimas

para desarrollar su capacidad creativa,

descansar y ocupar su tiempo libre...

Carta mundial de la naturaleza (1982)

\section{RESUMEN}

El trabajo es la aplicación de la categoría ecocrítica en el estudio y la investigación de la literatura hispanoamericana. La importancia de la ecocrítica cada día es más manifiesta, en especial porque ofrece una nueva categoría para el análisis de la literatura, una de las novedosas posturas contemporáneas que adoptan una preocupación social, cultural e interdisciplinar. Esto significa que las interrelaciones entre las esferas culturales, sociales y de entorno natural deben ser repensadas de manera simultánea para obtener la reconstrucción de las relaciones humanas con todos los estratos y tomar en cuenta un contexto global. Desde este punto de vista proponemos analizar textos de

1 Profesor de Castellano y escritor chileno. Estudió Literatura en la Universidad de Concepción (Chile) y en el Instituto Caro y Cuervo de Bogotá (Colombia). Es profesor titular de Literatura Chilena e Hispanoamericana en la Universidad del Bío-Bío. Ha publicado numerosos libros y artículos en prestigiosas revistas. Sobresalen los dedicados a Nicanor Parra, Pablo Neruda, Pablo de Rokha, Gabriela Mistral, Eugenio María de Hostos, Gonzalo Rojas, Mariano Latorre, Francisco Coloane, Pedro Lastra, Luis Sepúlveda, Darío Oses, Eduardo Anguita, entre otros. Miembro correspondiente de la Academia Chilena de la Lengua, socio honorario de la Sociedad Chilena de Estudios Literarios (SOCHEL), Premio Regional de Artes Literarias «Baldomero Lillo», Medalla Claudio Arrau , Premio Municipal de Chillán. 
Mario Vargas Llosa, Pablo Neruda, Mariano Latorre, Nicanor Parra, Juan Pablo Riveros, entre otros.

\section{PALABRAS CLAVE}

Ecocrítica, literatura hispanoamericana, ecología social, medio ambiente

\section{ABSTRACT}

This paper offers an ecocritical analysis of contemporary Spanish American literary texts, including Zurzulita by Mariano Latorre (1920), «Oda a la erosión de la provincia de Malleco» by Pablo Neruda (1956), «Ecopoemas» by Nicanor Parra (1983), De la tierra sin fuegos by Juan Pablo Riveros (1986), El hablador by Mario Vargas Llosa (1987) and «Expansion» by Ernesto Cardenal (1992). It explores the way texts reflect humanity's interaction with the non-human world in an attempt to examine how they addresses humans and other elements of the ecosystem.

\section{KEYWORDS}

Ecocriticis, Spanish American Literary Texts, Ecosystem, Social Ecology

Al considerar las relaciones que ha establecido la ecología con diversos aspectos que permiten nuestra permanencia como integrantes de un ecosistema, verificamos que la asociación de esta disciplina con el arte, y específicamente con la literatura, no se ha realizado en Hispanoamérica plenamente en forma pertinente, a la luz del carácter interdisciplinario en boga de los estudios literarios. A partir de ese punto - y dado que nuestro planeta se encuentra aquejado por un evidente deterioro medioambiental que afecta tanto a los reductos urbanos como a las reservas forestales, aguas, climas, hielos, pampas, bosques, selvas y otras áreas - , nos hemos hecho el propósito de considerar como materia de estudio, desde una perspectiva ecocrítica, el aporte que realiza el corpus de la producción lírica y narrativa hispanoamericana a la ecología.

Junto con la aplicación de las políticas neoliberales de fines del siglo XX surgen crisis de diversa índole que afectan directamente al hombre. Se vincula a ellas el desinterés de este por lo que no sea el goce o el provecho inmediato y lucrativo conducente a explotar desmesuradamente los recursos y atenta, a la postre, contra la existencia humana.

Dentro de esta crisis, el profesor de la Universidad de Concepción Mauricio Ostria reconoce el nacimiento de un nuevo humanismo, «que 
lejos de competir con la ciencia y la tecnología busca integrarse a una comprensión más equilibrada del hombre en el mundo: un humanismo situado» (1988, p. 13). Entendemos por este humanismo una apertura hacia la diversidad y un respeto por ella. Sin embargo, la proclamación de ese respeto y valor por lo diverso no es tan verdadera. Son pocas las personas que luchan o defienden abiertamente esa diversidad: se sigue destruyendo el ecosistema llevando a la extinción a etnias y especies que viven directamente en contacto con la naturaleza. No obstante, en este contexto, una renovación crítica postula un discurso ecologista y ecológico tendiente a mirar la realidad de otra manera o con otros ojos. Fundamentalmente su orientación es de realizar una lucha de resistencia contra las expresiones más agresivas de la globalización y depredación del ecosistema. Este nuevo discurso ha hecho visible el impacto producido por las catástrofes naturales o deliberadas directa o indirectamente por una sociedad irresponsable.

Desde esta renovación crítica se gesta en el plano internacional la preocupación sobre los problemas que existen en relación con el medio ambiente: la calidad del aire, el aniquilamiento de la capa de ozono, el cambio climático, el agotamiento del agua, la lluvia ácida, la destrucción de los recursos forestales, vegetales, minerales y biológicos, la producción de alimentos transgénicos, etcétera; cuestiones ligadas directamente con nuestra supervivencia y futuro como especie ${ }^{2}$.

\section{Una nueva crítica}

La crítica literaria contemporánea es asistida por un sinnúmero de corrientes cuyos criterios de estudio imbrican una valoración ético-ideológica y de «calidad estética». Algunos ejemplos de estas posturas críticas son el análisis sociológico (Lukács, Goldman, Bajtín, Fernández Retamar), el estructuralista (Barthes, Greimas, Kristeva, Lotman), el análisis sicológico (Poulet), recepcionista (Eco, Iser, Jauss), análisis posestructuralista y deconstructivista (Lacan, Derrida, Foucault), neomarxista (Benjamín, Jameson), feminista (Kristeva), el análisis poscolonial (Said, Babha) o la modernidad líquida (Bauman), escuelas que, entre otras, han abierto fisuras epistemológicas al canon de la literatura y de la crítica.

2 Con la finalidad de detener el impacto nocivo mentado, en 1972 la Organización de las Naciones Unidas (ONU) formuló a escala mundial el primer llamado para preservar a la tierra del desastre ecológico: la Conferencia sobre el Medio Humano. En 1982 y en 1987, respectivamente, el llamado se fortaleció con la Carta Mundial de la Naturaleza y el Informe Brundtland, que planteaban una visión de desarrollo sustentable para resguardar la naturaleza presente y el futuro de la humanidad. Por la misma razón, el Acuerdo de Kioto (1997) fue sustituido por el Acuerdo de París (2015), que entrará en vigor en 2020, con la ratificación oficial por cada país entre abril de 2016 y abril de 2017. 
En el análisis literario contemporáneo influyen distintas corrientes de pensamiento, que otorgan a la crítica bases de apoyo suficientemente sólidas a fin de establecer otras propuestas de discernimiento y descubrimiento de lecturas posibles de una obra literaria.

La heterogeneidad de discursos de la literatura hispanoamericana hace que tomemos en cuenta nuevas ordenaciones teóricas, en especial su inscripción en las esferas de los aspectos culturales y sociales, a modo de dar cuenta de manera cabal de la ocurrencia de fenómenos discursivos e ideológicos de honda intensidad.

La ecocrítica es una nueva categoría para el análisis de la literatura, una de las novedosas posturas contemporáneas que adoptan una preocupación social, cultural e interdisciplinar. Naciente de la crítica anglosajona, la palabra ecocriticism proviene del ensayo de William Rueckert titulado Literature and Ecology: An experimen in Ecocriticism (1989). La ecocrítica cuyos referentes originales son ecocriticism o green criticism - se define como «el estudio de las relaciones entre la literatura y el medio ambiente» (Glotfelty y Fromm, 1996, pp. XIII). Esto es, abordar las relaciones del ser humano con la naturaleza, el arte, el mundo que lo rodea y con el cosmos. El interés de la ecocrítica se dirige a la revisión de nuestras obras literarias, según los vínculos, con el fin de colaborar en los esfuerzos ecológicos que se realizan para evitar la degradación del planeta debido al desarrollo industrial, científico y tecnológico.

En otros términos:

La ecocrítica es el estudio de las relaciones entre literatura y el entorno físico. Así como la crítica feminista examina el lenguaje y la literatura desde una perspectiva de conciencia de género y la crítica marxista se ocupa del modo de producción y de clase económica en su lectura de los textos, la ecocrítica toma un enfoque centrado en la tierra para sus estudios literarios (Glotfelty y Fromm, 1996, p. XIII).

Superando el paradigma antropocéntrico de otras perspectivas de estudio crítico, la ecocrítica, crítica ecologista o verde integra las producciones textuales a un sistema mayor que las tradicionales series literarias, culturales e históricas, desplazando la obra hacia una nueva valoración ecocéntrica, eje que conecta la obra y al autor con las matrices que los sustentan. Se trata, entonces, de recuperar la conexión entre la naturaleza y la cultura, y hacer visible las interrelaciones e integraciones de los soportes y elementos que aseguran la vida básica del planeta. El nexo entre literatura y naturaleza representa una unión primordial y telúrica del hombre con el paisaje y el entorno. Se trata de una conexión que permite conjugar el 
mundo exterior, mítico y sagrado de la naturaleza con el mundo interior e intelectual, donde el escritor y el lector se encuentran.

Interesa señalar que un libro capital en el examen de las materias literarias ecocríticas es la compilación que hacen Cheryll Glotfelty y Harold Fromm, en 1996, Ilamado The Ecocriticism Reader: Landmarks in Literary Ecology. En este volumen, al que hemos hecho mención anteriormente, se encuentran numerosos artículos que otorgan fundamento al estudio ecocrítico (entre ellos, el fundacional artículo de William Rueckert).

En la introducción al volumen, Glotfelty reflexiona acerca de la necesaria notación que implica el conocimiento de los problemas medioambientales en función de nuestro propio quehacer, puesto que las problemáticas ecológicas son producto del grado que ha alcanzado el desarrollo cultural y técnico de la humanidad. La producción literaria y crítica hispanoamericana, desde su quehacer habitual, aún no da cuenta acerca de los graves problemas que afectan al planeta; por lo tanto, proponemos volcar nuestras energías en el esclarecimiento de la obra literaria situándonos en dicho escenario. Si pensamos a la obra literaria como un procedimiento del hombre para expresar sus ideas, pensamientos, cosmovisión y deseos por medio del arte del discurso y la palabra, este sujeto debe dar cuenta, con mayor razón, del riesgo que corre su precaria condición orgánica, independientemente de las consideraciones existenciales, sociopolíticas, religiosas, étnicas, de clase y de género, que le son propias.

Recordemos que la crítica literaria ha cumplido históricamente con la función primordial de ser un intermediario o mediador entre el texto y su receptor. Sin embargo, la ecocrítica busca mediar entre los autores, sus textos, la biósfera y el lector, estableciendo críticamente las conexiones y puentes de enlace entre el sujeto y el entorno. Los respectivos campos de contenido y esferas de acción en la dicotomía conciencia antropológica/conciencia ecológica - a las que Glen Love denomina egoconciencia y ecoconciencia (1996, p. 233), respectivamente- deben revertirse de modo urgente, ya que el predominio de la primera por sobre la segunda reproduce el desequilibrio al que hemos hecho referencia. Por lo tanto, corresponde realizar el tránsito desde la ego conciencia a la ecoconciencia, esto es, evolucionar desde una conciencia especular y narcisista a una conciencia habitada por la real identificación del hombre con su matriz natural.

\section{Prácticas discursivo-textuales}

La relación entre sociedad y naturaleza es ostensible. El filósofo francés Félix Guattari, en su ensayo Las tres ecologías (1990), sugiere que debemos aprender a pensar transversalmente las interacciones entre el ecosistema y el universo de referencias sociales e individuales en el que 
estamos insertos. Esto significa que las interrelaciones entre las esferas culturales, sociales y de entorno natural deben ser repensadas de manera simultánea para obtener la reconstrucción de las relaciones humanas con todos los estratos y tomar en cuenta un contexto global atribulado.

Guattari ejemplifica lo anterior con los desastres de la «ecología social» (entendida como la praxis social de una nueva visión del sistema de valores que busque una nueva salida de la historia) en los países del tercer mundo - y esto nos es cercano, porque que lo vivimos día a día-. La textura cultural de nuestras sociedades se ve disminuida y debilitada por las intervenciones foráneas, nuestros hábitats invadidos y saqueados por «nuevos conquistadores», nuestros niños y jóvenes abandonan sus comunidades para buscar sustento y se sumergen en las cosmópolis que, contradictoriamente les han sido hostiles a sus lugares de origen. Las comunidades prácticamente desaparecen, puesto que no hay población para darles la singular vida orgánico-social que las caracterizaba. Siguiendo esta lógica, Guattari indica que no solo desaparecen especies, sino también lenguas, palabras, frases, gestos de solidaridad humana, bases fundamentales para el desarrollo social (2006, p. 12).

En virtud de estos postulados, creemos conveniente y oportuno establecer una selección significativa que implique construir una red o serie textual desde una óptica ecológica hasta una ecologista, que implique, en un trabajo posterior, ciertos puntos cardinales del controversial tema de la naturaleza y de la discusión de sus problemáticas.

Debiéramos incluir en nuestro estudio diversas escrituras creativas hispanoamericanas, además de las citadas. Su elección sería independiente del género, de las periodizaciones y tendencias instituidas. Así podríamos ver que, paradigmáticamente, la preocupación por la naturaleza de Mariano Latorre (1886-1955), fundador en Chile de la literatura criollista, es transversal en los diferentes periodos de desarrollo literario, puede verse representada incluso en una escritura «posboom» ${ }^{3}$. Desde este prisma, la literatura es un sistema orgánico que, en evolución continua, está sujeta también a los vaivenes que se producen en la relación del hombre con su medio.

Corresponde entonces puntualizar las prácticas discursivo-textuales que se identifican con una escritura cuyo propósito es la visión de la naturaleza, como un objeto en constante dinamismo, y la interacción del

3 Uno de los escritores es el chileno Luis Sepúlveda. Podemos considerar, además, una novela prospectiva 2010: Chile en llamas, de Darío Oses, quien a través del reciclaje de temas construye una ficcional versión chilena del fin de la historia. En tal instancia, asistiríamos a una operación de interdiscursividad, una nueva modulación de un discurso anterior. 
hombre con esta. Aplicando las ideas y presupuestos de la ecocrítica, corresponde seleccionar un corpus formado por diversas obras de autores hispanoamericanos, tanto en prosa como en verso, que nos permitan inferir que la preocupación por la naturaleza en la literatura, sea en términos objetuales, pictórico-realistas, simbólico-poéticos o ideológicos, constituye una serie discursivo-textual centrada e identificable con lo que llamaremos discurso de la Tierra.

Un ejemplo claro de la desaparición de lenguas, palabras, frases y gestos lo encontramos en la novela El hablador (1991), de Mario Vargas Llosa, quien, refiriéndose al polémico y cuestionado Instituto Lingüístico de Verano, dice:

Los lingüistas eran algo muy diferente. Tenían, detrás de ellos, un poder económico y una maquinaria eficientísima que les permitiría tal vez implantar su progreso, su religión, sus valores, su cultura. ¡Aprender las lenguas aborígenes, vaya estafa! ¿Para qué? ¿Para hacer de los indios amazónicos buenos occidentales, buenos hombres modernos, buenos capitalistas, buenos reformados? Ni siquiera eso. Solo para borrar del mapa sus culturas, sus dioses, sus instituciones y adulterarles hasta sus sueños. Como habían hecho con los pieles rojas y los otros, allá en su país. ¿Eso quería para nuestros compatriotas de la selva? ¿Que se convirtieran en lo que eran, ahora, los aborígenes de Norteamérica? ¿Que se volvieran sirviente y lustrabotas de los viracochas? (1997, p. 94).

Es interesante subrayar el concepto de hablador utilizado en la narración por el Nobel peruano. El relato apunta a la conservación y transmisión de la cultura de la selva por la vía oral que pone en práctica Mascarita, protagonista que siente fascinación por el legado cultural indígena. Recurre al relato oral y se convierte en un contador ambulante de historias, un hablador. Según sabemos:

La narración es de particular importancia en las culturas orales primarias porque es capaz de reunir una gran cantidad de conocimientos populares en manifestaciones relativamente sustanciales y extensas que resultan razonablemente perdurables, lo cual en una cultura oral significa formas sujetas a repetición (Ong, 2006, p. 138).

Por tanto, «el hablador» o mediador identificado con el autor es un personaje que sirve para mantener la memoria colectiva de indios amazónicos, impidiendo la penetración extranjera, externa que altera la cultura arraigada del hombre, en el sentido de que esta ha funcionado en relación simbiótica con su medio ambiente. En términos ideales, el hablador mantiene mitos, magias y redes de relaciones que existen entre los individuos de las comunidades en peligro de extinción. 
Remitámonos a lo que nos narra Vargas Llosa:

El hablador, o los habladores, debían de ser algo así como los correos de la comunidad. Personajes que se desplazaban de uno a otro caserío, por el amplio territorio en el que estaban aventados los machiguengas, refiriendo a unos lo que hacían los otros, informándoles recíprocamente sobre las ocurrencias, las aventuras y desventuras de esos hermanos a los que veían muy rara vez o nunca. El nombre los definía. Hablaban. Sus bocas eran los vínculos aglutinantes de esa sociedad a la que la lucha por la supervivencia había obligado a resquebrajarse y desperdigarse a los cuatro vientos. Gracias a los habladores, los padres sabían de los hijos, los hermanos de las hermanas, y gracias a ellos se enteraban de las muertes, nacimientos y demás sucesos de la tribu (1997, p. 90).

No solo el peruano apunta a la conservación de los pueblos, también lo hace el poeta chileno Nicanor Parra. Puntualicemos que el crítico inglés Niall Binns, comentando el interés del antipoeta por el ecologismo, indica lo siguiente:

Como eje de su discurso ecologista, Parra adoptó dos lemas que serían repetidos en numerosos ecopoemas y entrevistas a lo largo de los años 80 y 90 . El primero rescata las célebres palabras de Seattle, jefe de los indios Suquamish, que en 1856 se vio forzado a vender sus tierras («pues sabemos que de no hacerlo, el hombre blanco vendrá con armas y tomará nuestra tierra»), expresando sin embargo su incredulidad ante la noción de compra venta de la tierra, porque «una cosa sabemos: que la tierra no le pertenece al hombre. Es el hombre el que pertenece a la tierra». El texto de Parra, afirma: «el error consistió / en creer que la tierra era nuestra / cuando la verdad de las cosas / es que nosotros somos de la tierra». El segundo de los lemas corresponde al comienzo de la llamada Propuesta de Daimiel, la declaración de principios redactada en 1978 por la federación del movimiento Ecologista del Estado Español (Binns, 2006, pp. LXIX-LXX)

Ahora bien, de acuerdo con el pensamiento planteado, es evidente, que «el tema ecológico no puede ser separado de la cuestión étnica» (Marrero, 2010, p. 202), tal como lo hace el chileno Juan Pablo Riveros en su importante obra De la tierra sin fuegos (1986), quien rescata la sabiduría ecológica de los pueblos originarios del extremo austral del continente, que fueron extinguidos por el hombre blanco explotador, pero cuya cultura sobrevive al genocidio en la memoria colectiva. El libro reivindica las leyendas y los mitos de onas, alacalufes y yaganes, antiguos habitantes de la Patagonia:

A los buscadores de oro, Auri Sacra Fames, siguieron otros enemigos de los indios 
más perversos y más poderosos: Los Estancieros.

Colonización «que descansó

en robo a gran escala»

Extensas llanuras cercadas. Despojados

los onas de sus cotos de caza. Ellos,

que poseían estos bienes inmuebles «de manera

que ni siquiera sabían que fuesen bienes inmuebles...»

jamás reclamaron título legal alguno (1986, p. 64).

Creemos que la vinculación del proyecto económico-neoliberal con las «raíces» tiene efectos nocivos. La intervención cultural foránea en pueblos incontaminados puede producir modificaciones, alteraciones y desarraigos en una comunidad en relación con sus costumbres y orígenes, como ocurre con la tribu de los indios machiguengas de la Amazonía peruana, según Mario Vargas Llosa.

Desde la perspectiva expuesta, los procesos sociales e históricos son procesos ecológicos. Esto se aclara si pensamos que la economía humana es solo una parte de un dominio más elaborado, vasto y complejo de la «economía global de la naturaleza».

El poeta nicaragüense Ernesto Cardenal, en una obra de 1970, ya ha materializado su preocupación por los vínculos contra el ser humano y los elementos cósmicos: «¿Volverá algún día Manco Cápac con su arado de oro? / ¿Y el indio hablará otra vez» (p. 61). En el poema «Expansión» (1992), texto muy posterior, amplía el espectro de la mutación del ser humano y su proyección hasta el infinito. Nuestros cuerpos se convierten en estrellas:

Nuestra carne y nuestros huesos vienen de otras estrellas

y aun tal vez de otras galaxias,

somos universales,

y después de la muerte contribuiremos a formar otras estrellas

y otras galaxias.

De las estrellas somos y volveremos a ellas (p. 31).

La relación entre el hombre y la superficie terrestre, en la que se pone a prueba resistencia en el proceso de supervivencia o inadaptabilidad, se ofrece en el cambio de vida del protagonista de Zurzulita del pueblo a la cordillera de la costa. Mateo, el personaje principal, no es capaz de resistir las durezas campesinas y, determinado telúricamente, perece de una manera trágica. En los relatos de Mariano Latorre:

«el hombre debe conocer la constitución de los organismos y fuentes que propician su subsistencia, pero, al mismo tiempo, su modo 
de vida; caso contrario, el hombre sucumbe por la imposibilidad de adecuarse a la forma de vida que le impone una naturaleza que acoge o rechaza a las especies que la habitan de manera permanente o momentánea» (Araya, 2011, p. 55).

\section{El crítico Arnaldo Donoso expresa:}

La red de preferencias y exclusiones de la escritura de Latorre acoge una acusada reflexividad. Las fuerzas expresivas de la novelística latorriana nacen del análisis del paso del ser humano por los espacios naturales. Para Araya, el determinismo telúrico implica no solo la visión evolutiva, sino también un conocimiento profundo, material y experiencial del orden y economía de la naturaleza (2015, p. 112).

Estimamos que para una mayor precisión es conveniente denominar Discurso de la Tierra, en forma genérica, a un conjunto de fenómenos de enunciación que inciden en la apropiación y en los modos de abordar y apreciar la naturaleza. Sustentamos que el discurso de la Tierra está presente en obras como Cuentos andinos (1920), de Enrique López Albújar; Huasipungo (1934), de Jorge Icaza; El mundo es ancho y ajeno (1941), de Ciro Alegría, entre otras. Es una serie textual que tiene una mirada de los contornos materiales. Sin embargo, este discurso en otros narradores posteriores se interioriza para llegar a la postre al reclamo por el deterioro del patrimonio y a una honda reflexión poética del territorio como la que realiza José María Arguedas en Los ríos profundos ${ }^{4}$ (1958) acerca de la cultura andina. Para estos efectos, se debieran establecer en un trabajo posterior relaciones interdisciplinarias de carácter ecológico, literario, ético, estético, sociológico, antropológico, político y cultural.

En la misma línea de apreciación, Pablo Neruda en su poema «Erosión en la provincia de Malleco»:

emprende un mítico viaje de regreso a los orígenes y a la tierra que lo vio crecer y advierte los efectos de la erosión hídrica y la quema indiscriminada del bosque nativo por parte de los hacendados, hechos que trastornan la superficie del suelo patrio. Neruda recurre, para poner aún más de manifiesto esta cruel realidad, a una evocación del paisaje de antaño, contrastándolo con el fenómeno que se devela ante sus ojos. La montaña boscosa, compuesta por maitenes, avellanos, raulíes, cipreses, laureles, mañío, robles, ulmos metidos en su espesura con «pájaros cantores» incluidos, se encuentra llena de cicatrices, desértica, destruida y arrasada.

4 Pedro Lastra cuenta: «a mediados de 1967 iniciamos en la Editorial Universitaria la serie Letras de América con Los ríos profundos. Para nosotros, el acontecimiento era importante y, aún más, que José María estuviera dispuesto a dar una conferencia en el salón de honor de la Universidad de Chile». 
La representación que hace Neruda de esta naturaleza es elegiaca, pues configura desde una conciencia ecologista, un lamento por que la «copa originaria» de la vida ha sido quemada y asesinada (Araya, 2006: 256).

El poeta Neruda en la oda en cuestión entrega poéticamente una horrorosa mirada acerca de una erosión que no ofrece ningún futuro:

\author{
Ahora, \\ siente \\ y toca \\ mi corazón \\ tus cicatrices, \\ robada la capa germinal \\ del territorio, \\ como si lava o muerte \\ hubieran roto \\ tu sagrada substancia \\ o una guadaña \\ en tu materno rostro \\ hubiera escrito \\ las iniciales del infierno (1956, p. 1041).
}

En suma, esta mirada ecocrítica ofrece enfoques de la literatura de Hispanoamérica, al mismo tiempo que actualiza el corpus literario hispanoamericano. Los textos distanciados temporalmente y a la luz del aparato crítico empleado conforman un ciclo de escrituras ejemplares acerca de la naturaleza. Estas son escrituras éticas que plasman una visión más contemporánea incluyendo, literariamente, los conflictos latentes de una naturaleza amenazada. Hay una literatura ecológica o ecologista que, apropiándose de la realidad natural, posee una sensibilidad que no parecía relevante a los ojos de algunos sectores de la crítica. Por lo tanto, propiciamos una lectura de la literatura hispanoamericana que tenga como objetivo describir el proceso de reinvención, entendimiento y desciframiento de las claves que vinculan al creador, al receptor, a la sociedad y a la cultura con el entorno ambiental. 


\section{REFERENCIAS BIBLIOGRÁFICAS}

Araya, J. (2006). Ética, política y poética: Hacia una lectura ecocrítica de Pablo Neruda. Revista de Crítica Literaria Latinoamericana, 63-64, pp. 253-264.

(2011). Novela de la tierra: consideraciones ecocríticas sobre Zurzulita (1920) de Mariano Latorre. Anales de Literatura Chilena, 12, pp. 49-60.

Binns, N. (2006). Introducción: ¿Por qué leer a Nicanor Parra? En N. Parra. Obras completas y algo +. Barcelona: Galaxia Gutenberg.

Cardenal, E. (1970). Homenaje a los indios americanos. Santiago de Chile: Editorial Universitaria.

(1999). Cantico cósmico. Madrid: Trotta.

Donoso, A. (2015). Estudios literarios ecocríticos, transdiciplinaridad y literatura chilena. Acta Literaria, 51, pp. 103-118.

Glotfelty, C. y Fromm, H. (Eds.) (1996). The Ecocriticism Reader: Landmarks in Literary Ecology. Athens y Georgia: University of Georgia Press.

Guattari, F. (1998). Las tres ecologías. Valencia: Pre-Textos.

Lastra, P. (2016). Una vida entre libros: letras de América. Santiago de Chile: Fondo de Cultura Económica.

Latorre, M. (1969). Zurzulita. Santiago: Nascimento.

Love, G. (1996). Revaluing nature. En Ch. Glotfelty y H. Fromm (Eds.). The Ecocriticism Reader: Landmarks in Literary Ecology. Athens y Georgia: University of Georgia Press.

Marrero, J. (2010). Ecocrítica e hispanismo. En C. Flys, J. Henríquez (Eds.). Ecocríticas, literatura y medioambiente. Madrid: Iberoamericana Vervuert.

Neruda, P. (1956). Obras completas. Buenos Aires: Losada.

Ong, W. (2006). Oralidad y escritura. Buenos Aires: Fondo de Cultura Económica.

Oses, D. (1998). 2010: Chile en llamas. Santiago: Planeta.

Ostria, M. (1988) Escritos de varia lección. Concepción: Ediciones Sur

Parra, N. (2011). Obras completas y algo +. Barcelona: Galaxia Gutenberg.

Riveros, J. (1986). De la tierra sin fuegos. Concepción: Libros del Maitén.

Vargas Llosa, M. (1997). El hablador. Barcelona: Seix Barral. 